\title{
Use of Mixture Design with Minimal Restrictions to Optimize an Extraction Procedure Employing Diluted Acids Assisted by Ultrasound and Microwave for Nutrient Element Determination in Vegetal Samples
}

\author{
Vinícius C. Costa, ${ }^{a}$ Erik G. P. Silva, ${ }^{a}$ Daniel C. Lima, ${ }^{a}$ Marcelo Franco, ${ }^{a}$ \\ Raildo M. Jesus, ${ }^{a}$ Marcos A. Bezerra ${ }^{b}$ and Fábio A. C. Amorim*,a \\ a'Departamento de Ciências Exatas e Tecnológicas, Universidade Estadual de Santa Cruz, \\ Rodovia Jorge Amado, km 16, 45662-900 Ilhéus-BA, Brazil \\ ${ }^{b}$ Departamento de Química e Exatas, Universidade Estadual do Sudoeste da Bahia, \\ 45200-190 Jequié-BA, Brazil
}

\begin{abstract}
In this work, it was developed an alternative analytical strategy for the preparation of vegetal samples extracted with diluted acids and assisted by ultrasound and microwave radiation for the determination of nutrients elements by fast sequential flame atomic absorption spectrometer. The conditions optimized using univariate and multivariate methodologies for the procedure were as follows: $200 \mathrm{mg}$ of sample; extraction solution comprising a mixture of $6.3 \mathrm{~mL} \mathrm{HNO}_{3}, 2.1 \mathrm{~mL} \mathrm{HCl}$, and $1.7 \mathrm{~mL} \mathrm{CH} \mathrm{CHOH}_{3} \mathrm{CO}$; exactor with a final concentration of $2.5 \mathrm{~mol} \mathrm{~L}^{-1}$; a sonication time of $30 \mathrm{~min}$; and a microwave radiation time of $6 \mathrm{~s}$. The accuracy of the procedure was confirmed by analyzing the certified reference material NIST 1515 (apple leaves) and by comparison with the results obtained through microwave-assisted total digestion method. The procedure was applied to determine $\mathrm{Ca}, \mathrm{Mg}, \mathrm{Cu}, \mathrm{Mn}, \mathrm{Fe}$, and $\mathrm{Zn}$ in several cassava peel samples used in animal nutrition, and proved to be simple, reliable, fast, easy to implement, and inexpensive.
\end{abstract}

Keywords: design mixture, diluted acids, ultrasound extraction, microwave, nutrient elements

\section{Introduction}

The most commonly used analytical techniques for the elemental determination of complex samples are flame atomic absorption spectroscopy (FAAS), inductively coupled plasma optical emission spectrometry, and inductively coupled plasma mass spectrometry. ${ }^{1}$ The preparation of vegetal samples for atomic spectrometric analyses is a critical step due to the high content of organic matter in their matrices, needing a sample pretreatment that involves total destruction of organic matter. Thus, the sample digestion methods involving the use of concentrated oxidizing acids, high temperatures, and high pressures are frequently used. ${ }^{2,3}$

Currently, one of the most important trends in sample preparation is the interest in analytical procedures that complies with the principles of green chemistry. Following this trend, the use of diluted acids has been shown to present significant advantages such as cost reduction, production

*e-mail: facamorim@uesc.br of smaller residue quantities, reduction of blank values, minimization of damage to devices, and lower acidity of digested samples. ${ }^{4}$

Considering the advantages of diluted acids, a range of recent applications have demonstrated their potential in sample preparation, e.g., employing digestion-assisted microwave for several samples, such as beans, ${ }^{5}$ pâté, ${ }^{6}$ milk and beef, ${ }^{7}$ honey, ${ }^{8}$ biological matrices,${ }^{9}$ milk, ${ }^{10}$ chocolate, ${ }^{11}$ plants, ${ }^{12}$ and fertilizers. ${ }^{13}$

Extraction procedure with diluted acids is another procedure used in the treatment of samples for analytical purposes and provides analytes through diluted reagents without the complete destruction of matrices. Several factors cause this to occur: sample composition, solvent type and concentration, extraction time, temperature, analyte characteristics, etc. The technique is simple, quick, safe, and inexpensive. The extraction procedures, if compared to wet digestion procedures, are subject to fewer problems involving solution blanks, present lesser volatile losses and smaller handling risks, minimize dilution factors, and reduce costs due to the low volume of reagents. ${ }^{14,15}$ 
In extraction procedures with diluted acid, there has been a greater use of acid mixtures because they potentialize the analytical response. ${ }^{16}$ When preparing experiments with acid mixtures, a mixture design is used in which the property systems depend upon ingredient proportions, rather than on their absolute values. Many times, it is not worth, or even possible, investigating all values in the proportion (from 0 to $100 \%$ ) of mixture components. Many problems arising from mixture optimization require the presence of all ingredients to produce a satisfactory product or to exclude experimental regions when it is impossible or pointless to obtain a combination of all factors. In those cases, it is convenient to define minimum restrictions for some components (minimal restrictions). ${ }^{17}$ Mixture designs have been used to optimize chromatography methods; $;{ }^{18,19}$ however, their application in other analytical chemistry areas has not been explored, and few studies are found in the literature. ${ }^{20,21}$

Normally, the dilute acid extraction procedures are used with ultrasound energy, which is based on the effect of acoustic cavitation. In this case, microbubbles nucleate, grow, and quickly collapse, generating a localized temperature increase. ${ }^{14,15}$ Thus, ultrasound-assisted dilute acid extraction has been used to prepare samples in several substances, such as marine invertebrates,${ }^{22}$ mussels, ${ }^{23}$ swine feed, ${ }^{24}$ slim teas, ${ }^{25}$ coconut milk, ${ }^{26}$ marine sediments, ${ }^{27}$ fortified food, ${ }^{28}$ chocolate bars,,$^{29}$ vegetable oils, ${ }^{30}$ and babassu coconut. ${ }^{31}$

This research describes the development of a simple procedure using ultrasound and microwave-assisted dilute acid extraction that uses a mixture design with minimal restrictions to determine $\mathrm{Ca}, \mathrm{Mg}, \mathrm{Fe}, \mathrm{Zn}, \mathrm{Cu}$, and $\mathrm{Mn}$, by fast sequential (FS) multi-element FAAS in cassava peels samples, which are used in animal feed.

\section{Experimental}

\section{Instrumentation}

A Varian model SpectrAA 240FS (Mulgrave, Victoria, Australia) fast sequential FAAS (FS FAAS) equipped with hollow cathode lamps as light sources was used in the respective wavelengths: $422.7 \mathrm{~nm}(\mathrm{Ca}), 285.2 \mathrm{~nm}(\mathrm{Mg})$, $324.8 \mathrm{~nm}(\mathrm{Cu}), 279.5 \mathrm{~nm}(\mathrm{Mn}), 248.3 \mathrm{~nm}(\mathrm{Fe})$, and $213.9 \mathrm{~nm}(\mathrm{Zn})$. Deuterium lamp background correction was also used. The flame composition was acetylene (flow rate: $2.0 \mathrm{~L} \mathrm{~min}^{-1}$ ) and air (flow rate: $13.5 \mathrm{~L} \mathrm{~min}^{-1}$ ). Nebulizer flow rate was $5.0 \mathrm{~mL} \mathrm{~min}^{-1}$.

A desiccation stove with air circulation (Odontobrás, Mogi das Cruzes, Brazil) was used to remove the humidity from the cassava peel samples. A Wiley mill of knives
(ACB LABOR, São Paulo, Brazil) was used to crush cassava peel samples and a ball mill 8000 (Spex Sample Prep, Metuchen, USA) was used to reduce the particle size. An analytical balance (Sartorius, Göttingen, Germany) was used to establish the sample mass. The sonication of the solutions was performed using a USC-1800 ultrasonic bath (Cortland, New York, USA). The equipment was filled with $2.8 \mathrm{~L}$ of water, and glass tubes were placed in the bath in the more intense cavitation region (previously mapped according literature recommendations). ${ }^{32} \mathrm{~A}$ domestic microwave oven model PMS24 (Philco, São Paulo, Brazil) with power settings from "low" to "high" (corresponding to 160 to $800 \mathrm{~W}$ of power output) was used to complete the extraction process. To obtain greater uniformity of distribution of the microwave radiation, a single bottle was placed inside the oven so that only the reaction bottle was exposed to the radiation. A centrifuge Model 5804 (Eppendorf, Berlin, Germany) equipped with 16 tubes $(50.0 \mathrm{~mL})$ was used to promote the extraction and separate the liquid from the solid phase. A microwave oven closedvessel model MDS 40 (Master Sineo, Zhejiang, China) equipped with 40 digestion tubes was used in the total digestion of the samples, with the aim to compare the efficiency of the extraction procedure.

\section{Reagents and solutions}

All of the reagents were of analytical grade and the solutions were prepared using high purity water that had a resistivity of $18.2 \mathrm{M} \Omega \mathrm{cm}$, obtained from a Milli-Q Plus water purification system from Millipore (Bedford, MA, USA). The analyte solutions used for external calibration were prepared from $1000 \mathrm{mg} \mathrm{L}^{-1}$ standard solutions (Merck, Darmstadt, Germany). Appropriate dilutions were made from the standard solutions, and these solutions were stored in polyethylene flasks under refrigeration. Diluted acid solutions of $\mathrm{HNO}_{3}, \mathrm{HCl}$, and $\mathrm{CH}_{3} \mathrm{COOH}$ of $0.5,1.0$, $1.5,2.0$, and $2.5 \mathrm{~mol} \mathrm{~L}^{-1}$ concentrations were prepared by dilution in high-purity water. All laboratory glassware was soaked in $\mathrm{HNO}_{3}(10 \% \mathrm{v} / \mathrm{v})$ solution for $24 \mathrm{~h}$, washed with deionized water, and dried before use.

\section{Sampling preliminary treatment of samples}

A total of nine cassava peel samples were obtained and analyzed. Of these, six samples were collected directly from farms that use cassava peel in dairy cattle feed. Each sample was collected from farms located in different cities of South Bahia State, Brazil: Teixeira de Freitas, Alcobaça, Itamaraju, Eunápolis, Mucuri, and Nova Viçosa. The samples were washed with tap water and deionized water 
and dried in a stove with air circulation at $60^{\circ} \mathrm{C}$ for $24 \mathrm{~h}$ to remove the humidity. Subsequently, they were ground in a knife mill and subjected to a ball mill to reduce particle size and then sieved on nylon mesh (pores: $300 \mu \mathrm{m}$ ). Finally, the samples were transferred to previously decontaminated polyethylene tubes and stored in desiccators. Samples bioprocessed with filamentous fungi Aspergillus niger and Aspergillus oryzae were provided by the Reuse of Waste Agribusiness Laboratory (LABRA) of Bahia Southwest State University (UESB), Itapetinga campus. The certified reference material (CRM) NIST 1515 (apple leaves) was used to assess the accuracy of the procedure.

\section{Strategy for the procedure optimization}

The optimization of the extraction procedure of all elements $(\mathrm{Ca}, \mathrm{Mg}, \mathrm{Cu}, \mathrm{Fe}, \mathrm{Mn}$, and $\mathrm{Zn}$ ) was realized with cassava peel samples, and using two types of methodologies: (i) univariate methodology was used to study the following variables: extractor type $\left(\mathrm{HNO}_{3}, \mathrm{HCl}\right.$, and $\left.\mathrm{CH}_{3} \mathrm{COOH}\right)$, extractor concentration $(0,0.5,1.5$, 2.0 , and $\left.2.5 \mathrm{~mol} \mathrm{~L}^{-1}\right)$, sonication time $(0,10,20,30$, and $40 \mathrm{~min})$, and microwave irradiation time ( $0,2,3$, and $6 \mathrm{~s})$; and (ii) multivariate optimization was used to improve the performance of the procedure by applying mixture design with minimal restrictions on the optimization of the volumes of extractor solution composed by mixture of $\mathrm{HNO}_{3}, \mathrm{HCl}$, and $\mathrm{CH}_{3} \mathrm{COOH}$, and a minimum restriction of $4.0 \mathrm{~mL}$ for $\mathrm{HNO}_{3}, 1.0 \mathrm{~mL}$ of $\mathrm{HCl}$, and $1.0 \mathrm{~mL}$ for $\mathrm{CH}_{3} \mathrm{COOH}$ (Figure 1) was considered. Software Statistica $8.0^{33}$ was used to analyze the data.

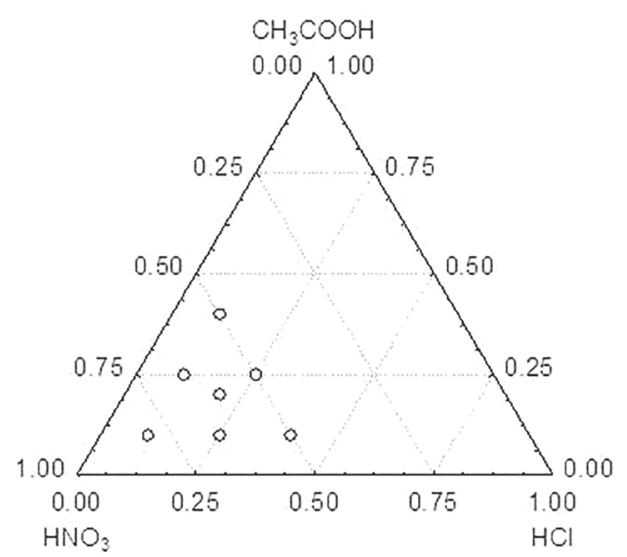

Figure 1. Experimental region from mixture design delimited by minimal restrictions established for each component.

The use of design mixtures is justified because the presence of three components generates a better response than a pure component. In some cases, it is impossible to perform some experiments with the complete mixture design because this would demand the use of a pure component. ${ }^{16}$

To allow the simultaneous optimization of the six obtained responses, a mathematical approach developed by Derringer and Suich ${ }^{34}$ was used. The approach is based on desirability functions applied in optimizing multiresponse experiments. The approach first converts each response $\left(\mathrm{y}_{\mathrm{i}}\right)$ into an individual desirability function $\left(\mathrm{d}_{\mathrm{i}}\right)$, which varies within the range of $0 \leq \mathrm{d}_{\mathrm{i}} \leq 1$. If the response is desired, the function value is $d_{i}=1$, and if the response is outside the acceptable region, $d_{i}=0$. The individual desirability $\left(\mathrm{d}_{\mathrm{i}}\right)$ is calculated according to equation 1 :

$d=\left\{\begin{array}{l}0 \text { if } y<L \\ \left(\frac{y-L}{T-L}\right)^{s} \text { if } L \leq y \leq t \\ 1 \text { if } y>T\end{array}\right.$

where $\mathrm{L}$ is the lowest acceptable value for the response, and $\mathrm{s}$ is the weight (when equal to 1 : linear desirability function). In this work, L values were the lowest recovery found in a set of experiments for each element, and $\mathrm{T}$ values were the highest recovery for each element.

Later the overall desirability (OD) is calculated according to equation 2 :

$$
\mathrm{D}=\sqrt[m]{\mathrm{d}_{1} \mathrm{~d}_{2} \ldots \mathrm{d}_{\mathrm{m}}}
$$

where $\mathrm{m}$ is the number of response variables.

\section{Sample preparation}

\section{Extraction procedure}

The extractions were performed in triplicate according to the following procedure: $200 \mathrm{mg}$ of each sample was accurately weighed in tubes with capacity of $15.0 \mathrm{~mL}$. Then, the sample was added to $10.0 \mathrm{~mL}$ of the extracting mixture, with a final concentration of $2.5 \mathrm{~mol} \mathrm{~L}^{-1}$ comprising $6.2 \mathrm{~mL}$ of $\mathrm{HNO}_{3}, 2.1 \mathrm{~mL}$ of $\mathrm{HCl}$, and $1.7 \mathrm{~mL}$ of $\mathrm{CH}_{3} \mathrm{COOH}$. The tubes were placed in an ultrasonic bath for $30 \mathrm{~min}$ (frequency of $20 \mathrm{kHz}, 80 \mathrm{~W}$ power, and temperature of $30 \pm 1{ }^{\circ} \mathrm{C}$ ). Subsequently, the solutions were subjected to microwave irradiation for $6 \mathrm{~s}$ using $600 \mathrm{~W}$ power. Finally, the samples were centrifuged for $2 \mathrm{~min}$ at $2000 \mathrm{rpm}$, and the supernatant was filtrated and submitted for analysis by FS FAAS.

\section{Microwave-assisted digestion}

The digestions were performed in triplicate according to the following procedure: $200 \mathrm{mg}$ of each sample were 
accurately weighed in digestion tubes and $3.0 \mathrm{~mL}$ of $\mathrm{HNO}_{3}$ $(65 \% \mathrm{v} / \mathrm{v})$ and $2.0 \mathrm{~mL}$ of $\mathrm{H}_{2} \mathrm{O}_{2}(30 \% \mathrm{v} / \mathrm{v})$ were added. The samples underwent the total digestion process in a microwave oven with a cavity, under the heating program as indicated by the manufacturer, as described: step 1: time $8 \mathrm{~min}$, power $500 \mathrm{~W}$, and temperature $120^{\circ} \mathrm{C}$; step 2: time $26 \mathrm{~min}$, power $750 \mathrm{~W}$, and temperature $180^{\circ} \mathrm{C}$. After this procedure, the digested samples were transferred to polyethylene tubes and the volumes were increased to $20.0 \mathrm{~mL}$ with ultrapure water.

\section{Results and Discussion}

\section{Optimization of extractor type and concentration}

Preliminary studies involving the type and concentration of the extractor were conducted. In these studies, individual solutions of $\mathrm{HNO}_{3}, \mathrm{HCl}$, and $\mathrm{CH}_{3} \mathrm{COOH}$ in concentrations ranging from 0 to $2.5 \mathrm{~mol} \mathrm{~L}^{-1}$ were studied with intervals of $0.5 \mathrm{~mol} \mathrm{~L}^{-1}$. For all the extractors, the extraction significantly increased with an increase in concentration. $\mathrm{HNO}_{3}$ (concentration of $2.5 \mathrm{~mol} \mathrm{~L}^{-1}$ ) showed a more marked effect on the analytical response. Thus, $\mathrm{HNO}_{3} 2.5 \mathrm{~mol} \mathrm{~L}^{-1}$ was used in further research.

\section{Sonication time optimization}

The effect of sonication time in the extraction procedure was studied with a time range of 0 to $40 \mathrm{~min}$, with $10 \mathrm{~min}$ intervals. A significant increase in the analytical signal was observed after $10 \mathrm{~min}$ of sonication, with the maximum response occurring at $30 \mathrm{~min}$. Thus, $30 \mathrm{~min}$ of sonication was used in subsequent steps. At $40 \mathrm{~min}$ of sonication, a decrease in the analytical signal was observed for all elements except $\mathrm{Cu}$ (Figure 2). Such a phenomenon may occur because different species can be formed when submitted to a longer sonication time, which can cause the recombination of different structures in the liquid phase and form new solid or as chelating agents species, reducing the ions present in the liquid phase, which do not contribute to increase the analytical signal. ${ }^{35}$

\section{Optimization of microwave irradiation time}

Although sophisticated laboratory microwave ovens are available, simple domestic microwave ovens are widely used in sample preparation methods, e.g., online microwaveinduced digestion, ${ }^{36}$ microwave-assisted solubilization, ${ }^{37}$ total digestion in closed high-pressure microwave systems, ${ }^{38}$ and microwave-digestion screw cap polypropylene tubes. ${ }^{39}$ Recently, domestic microwave ovens and screw-capped polypropylene tubes were used for the microwave-assisted

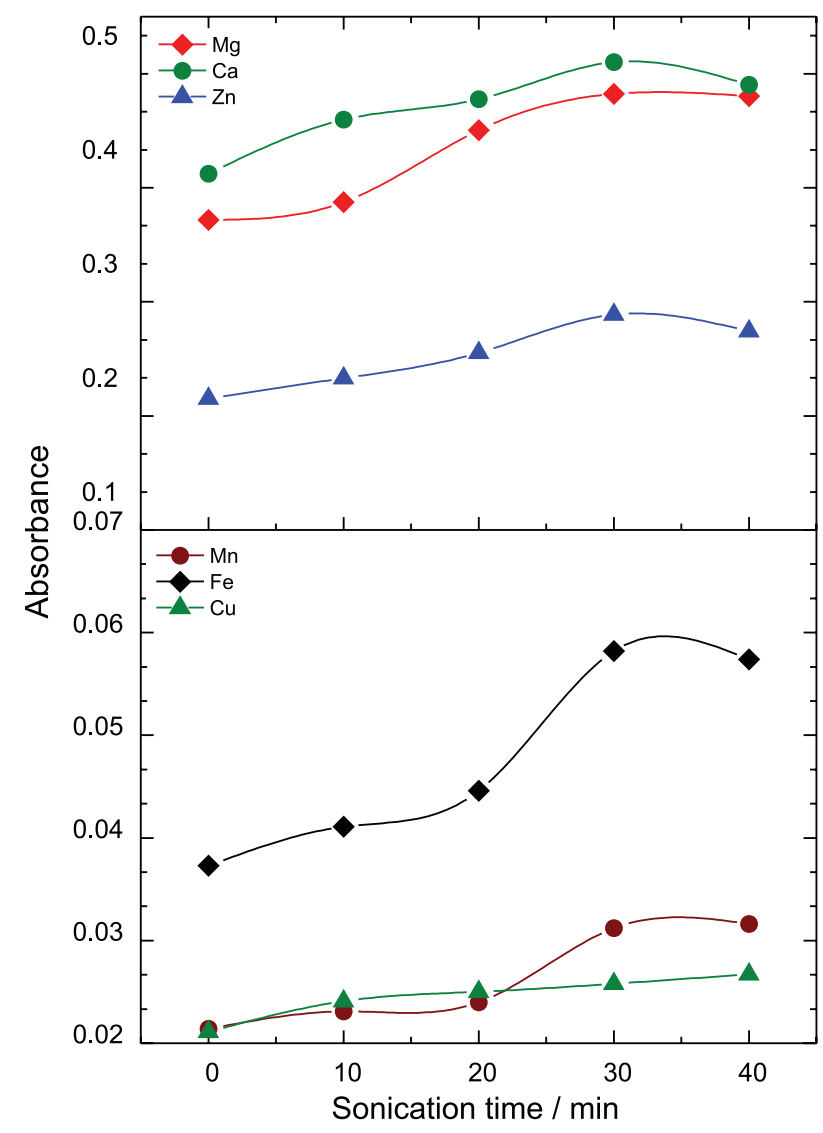

Figure 2. Effect of the sonication time on the analytical signal obtained for $\mathrm{Ca}, \mathrm{Mg}, \mathrm{Fe}, \mathrm{Zn}, \mathrm{Cu}$, and $\mathrm{Mn}$.

diluted acid extraction methods of elements in samples of fish, ${ }^{40}$ coal and coal-fly ash, ${ }^{41}$ and sediments, ${ }^{42}$ followed by their determinations via spectrometric techniques. The main advantages of using a domestic microwave oven are the low costs, the ease of acquisition, the use for different purposes (synthesis, extraction, heating), and the use with different configurations.

The influence of domestic microwave oven use in the increased analytical response was studied. Samples went through microwave irradiation for an interval from 0 to $6 \mathrm{~s}$, and the maximum analytical signal for all elements was obtained in $6 \mathrm{~s}$ (Figure 3). This result was expected because with an increase in radiation time, a gradual increase in temperature and pressure occurs in the reaction vessel, which in many cases potentiates the extraction of the analyte. In addition, the use of diluted acid also contributes significantly to the extraction of the analyte due to the dielectric capacity of water, which absorbs the microwave radiation and turns it into heat. ${ }^{43} \mathrm{It}$ is possible to observe that the analytical signals of $\mathrm{Ca}, \mathrm{Mg}, \mathrm{Cu}, \mathrm{Zn}$, and $\mathrm{Mn}$ showed slight increases. An intense signal was obtained for $\mathrm{Fe}$, demonstrating that the microwave has an important role in increasing signal strength for this analyte. Some research describing ultrasound-assisted extraction, point out the 
difficulty in extracting Fe using only ultrasonic radiation. In this case, the use of the domestic microwave is presented as a complementary strategy to the ultrasound..$^{24,28,31}$ It was not studied longer irradiation times because the reaction bottles suffered too much wear-and-tear after $8 \mathrm{~s}$.

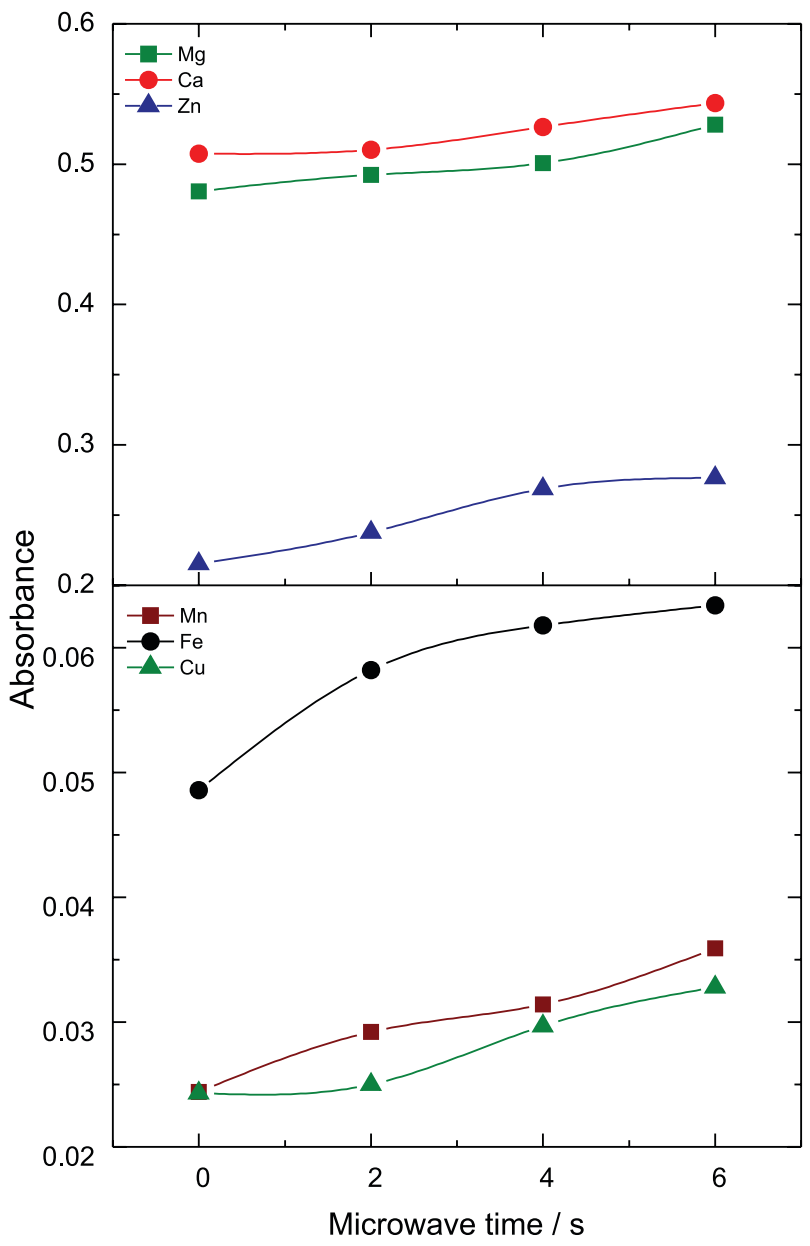

Figure 3. Effect of the microwave irradiation time on the analytical signal obtained for $\mathrm{Ca}, \mathrm{Mg}, \mathrm{Fe}, \mathrm{Zn}, \mathrm{Cu}$, and $\mathrm{Mn}$.

\section{Mixture design}

During the preliminary comparisons of the types of extractors, it was noted that individually, all of them were able to extract a certain amount of the analytes. Given these observations and some work in the literature using mixtures of acid solutions diluted in extraction procedures, we made a mixture design to investigate the influence of the interaction of acids on the extraction efficiency, since this can not be performed by univariate design. Thus, we used all the optimized conditions in the previous study by only changing the type of extraction solution.

Based on the preliminary studies for the optimization of the extraction solution, a mixture design with minimal restriction was selected, allowing restrictions of the components at minimum values. The minimum restriction for each component of the mixture was determined according to the responses obtained during the univariate study. In mixture design, the crucial step for the success of the procedure is the optimization of the appropriate proportions of extracting solutions.

The experiment matrix and the recovery values for the studied six elements are shown in Table 1. All recovery values and overall desirability were obtained in duplicate for each experiment in order to estimate the experimental error. The recovery values were calculated from reference values, which were obtained through microwave-assisted digestion.

The optimized conditions for each variable were evaluated through contour graphs using the mixture design with minimal restrictions, after the evaluation of mathematical model. Linear and quadratic mathematical models were fitted to the data generated for overall desirability to obtain the best description of the experimental region. To assess the quality of the model, the lack of fit was

Table 1. Mixtures matrix and responses, based in the average of recovery percentage \pm standard deviation, to optimize the volume of solutions of $\mathrm{HNO}_{3}$, $\mathrm{HCl}$, and $\mathrm{HAc}$ (acetic acid)

\begin{tabular}{|c|c|c|c|c|c|c|c|c|c|c|}
\hline \multirow{2}{*}{ Experiment } & \multicolumn{3}{|c|}{ Acid mixture / mL } & \multicolumn{6}{|c|}{ Recovery / \% } & \multirow{2}{*}{$\mathrm{OD}$} \\
\hline & $\mathrm{HNO}_{3}$ & $\mathrm{HCl}$ & HAc & $\mathrm{Ca}$ & $\mathrm{Mg}$ & $\mathrm{Cu}$ & $\mathrm{Fe}$ & $\mathrm{Mn}$ & $\mathrm{Zn}$ & \\
\hline 1 & 5.0 & 1.0 & 4.0 & $58.5 \pm 0.71$ & $83.5 \pm 2.12$ & $51.5 \pm 2.12$ & $49.0 \pm 1.41$ & $75.5 \pm 0.71$ & $54.5 \pm 2.12$ & 0.00 \\
\hline 2 & 8.0 & 1.0 & 1.0 & $62.0 \pm 2.83$ & $82.5 \pm 3.54$ & $85.5 \pm 2.12$ & $60.5 \pm 0.71$ & $70.5 \pm 0.71$ & $53.5 \pm 2.12$ & 0.00 \\
\hline 3 & 5.0 & 4.0 & 1.0 & $69.5 \pm 0.71$ & $87.5 \pm 0.71$ & $81.0 \pm 1.41$ & $76.5 \pm 2.12$ & $92.5 \pm 3.54$ & $68.0 \pm 2.83$ & 0.41 \\
\hline 4 & 5.0 & 2.5 & 2.5 & $89.5 \pm 2.12$ & $91.0 \pm 0.75$ & $81.5 \pm 2.83$ & $88.5 \pm 2.12$ & $97.5 \pm 0.71$ & $86.5 \pm 3.54$ & 0.68 \\
\hline 5 & 6.5 & 1.0 & 2.5 & $92.0 \pm 4.95$ & $91.0 \pm 4.24$ & $83.5 \pm 7.78$ & $86.5 \pm 0.71$ & $99.0 \pm 3.54$ & $91.0 \pm 2.12$ & 0.71 \\
\hline 6 & 6.5 & 2.5 & 1.0 & $97.5 \pm 0.71$ & $95.0 \pm 1.41$ & $95.0 \pm 1.41$ & $89.5 \pm 0.71$ & $94.5 \pm 0.71$ & $96.5 \pm 2.12$ & 0.83 \\
\hline 7 & 6.0 & 2.0 & 2.0 & $99.0 \pm 0.71$ & $101 \pm 2.12$ & $100 \pm 2.83$ & $105 \pm 0.75$ & $96.5 \pm 2.12$ & $96.5 \pm 0.71$ & 0.94 \\
\hline
\end{tabular}

OD: overall desirability. 
verified. If the model was well-fitted to the experimental data, the mean square of lack of fit $\left(\mathrm{MS}_{\mathrm{lof}}\right)$ should reflect only the random errors inherent to the system. Additionally, the mean square of pure error $\left(\mathrm{MS}_{\mathrm{pe}}\right)$ should also be an estimate of these errors and it is assumed that these two values are not statistically different. Thus, it is possible to use the $F$ distribution to assess whether there is any statistical difference between these two means. According to the analysis of variance (ANOVA) presented in Table 2, the linear model showed lack of fit $\left(F_{\text {calculated }}(4748)>F_{\text {tabled }}\right.$ (19.16)) and left large residues. Therefore, it presented low predictive capability. The quadratic model did not show lack of fit $\left(F_{\text {calculated }}(0.66)<F_{\text {tabled }}(5.59)\right)$, left smaller residues and demonstrated a good predictive capability.

The following quadratic equation illustrates the relation among the three component volumes of the studied mixtures and overall desirability. In equation 3 , terms in bold are not significant. They were not eliminated from the equation to allow calculation of the critial point.

$\mathrm{OD}=0.4182 \mathrm{VHNO}_{3}-\mathbf{0 . 0 0 0 4} \mathbf{V H C l}-$

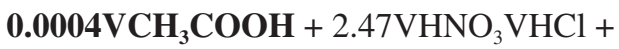
$2.03 \mathrm{VHNO}_{3} \mathrm{VCH}_{3} \mathrm{COOH}+2.75 \mathrm{VHClVCH}_{3} \mathrm{COOH}$

After the evaluation of the most adjusted mathematical model, the response surface and contour graphic was generated in terms of overall desirability (Figures $4 a-4 b$ ). It can be inferred that there is a relationship between the three volumes of the studied mixture components.

Figure 5 shows the individual and the overall desirability profiles. It was calculated acoording to the equations 1 and 2, where $\mathrm{L}$ was the lowest value found for each set of responses, $\mathrm{T}$ was the highest of these set and $\mathrm{s}$ was (a)
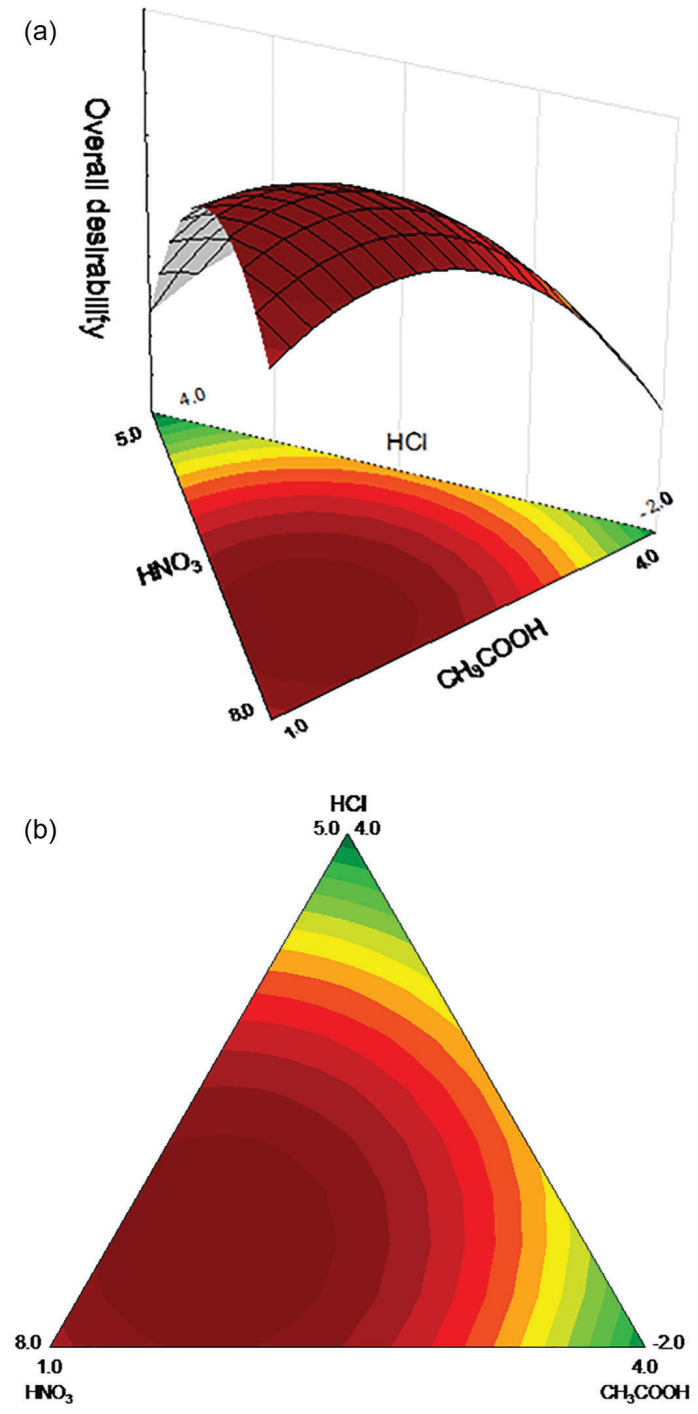

Figure 4. (a) Response surface and (b) contour plot for optimization of volume mixture components.

Table 2. Analysis of variance (ANOVA) for linear and quadratic models, fitted to overall desirability, with a 95\% confidence level

\begin{tabular}{|c|c|c|c|c|c|}
\hline Variation source & SS & df & MS & $F_{\text {calculated }}$ & $F_{\text {tabled }}$ \\
\hline \multicolumn{6}{|l|}{ Linear model } \\
\hline Model & 0.22921 & 2 & 0.11460 & 0.80 & 3.98 \\
\hline Total error & 1.56503 & 11 & 0.14227 & & \\
\hline Lack of fit & 1.56446 & 4 & 0.39111 & 4748 & 4.12 \\
\hline Pure error & 0.00057 & 7 & 0.00082 & & \\
\hline Total adjusted & 1.79425 & 13 & 0.13801 & & \\
\hline \multicolumn{6}{|l|}{ Quadratic model } \\
\hline Model & 1.19362 & 5 & 0.35872 & 4546 & 3.69 \\
\hline Total error & 0.00063 & 8 & 0.00007 & & \\
\hline Lack of fit & 0.00005 & 1 & 0.00005 & 0.66 & 5.59 \\
\hline Pure error & 0.00057 & 7 & 0.00008 & & \\
\hline Total adjusted & 1.79425 & 13 & 0.13801 & & \\
\hline
\end{tabular}

SS: sum of square; df: degree of freedom; MS: mean square. 

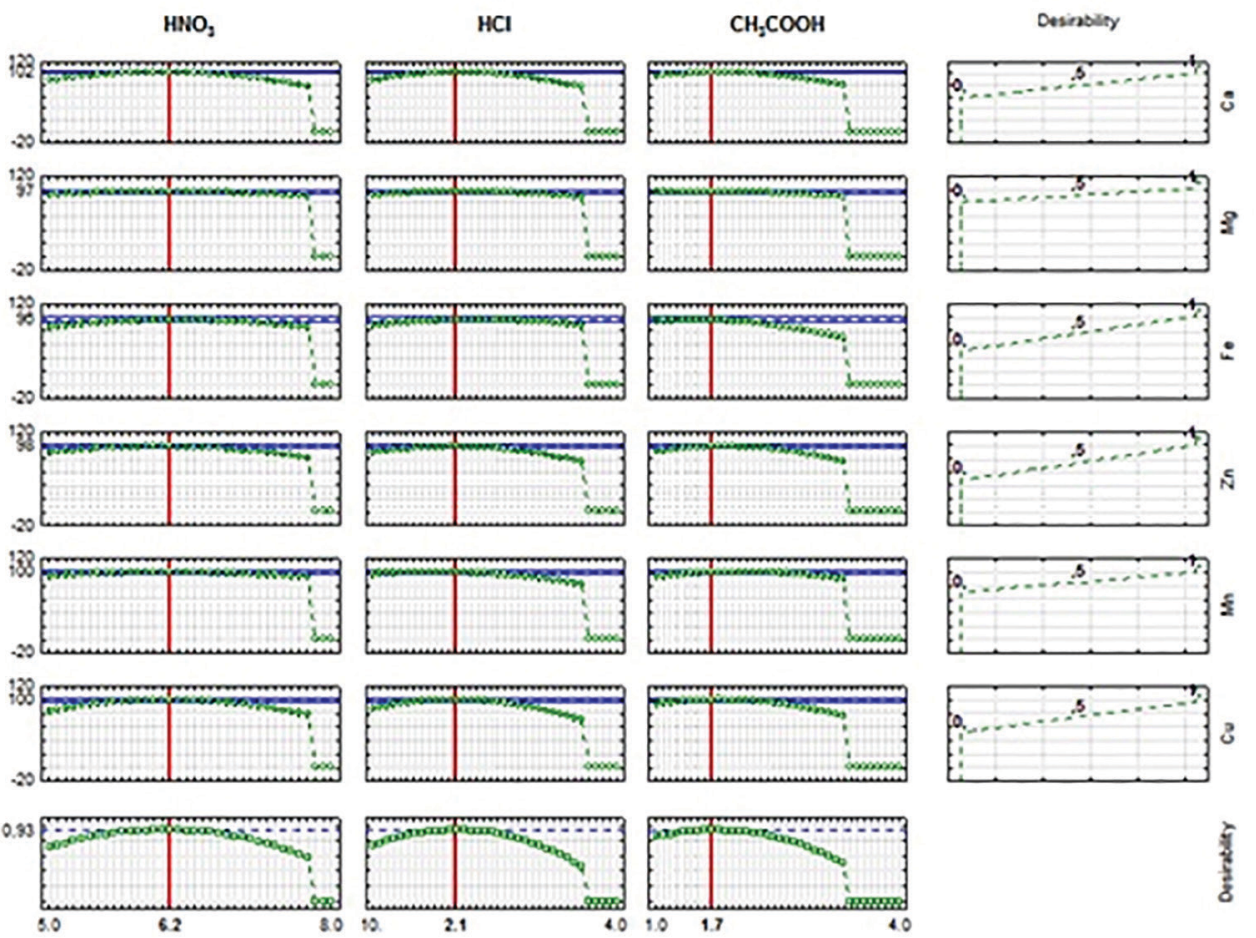

Figure 5. Profiles for predictive values, individual and overall desirability in optimizing the volume of the mixture variables.

equal to 1 . Analyzing this graph indicated that higher responses were obtained when $6.2 \mathrm{~mL}$ of $\mathrm{HNO}_{3}, 2.1 \mathrm{~mL}$ of $\mathrm{HCl}$, and $1.7 \mathrm{~mL}$ of $\mathrm{CH}_{3} \mathrm{COOH}$ are utilized. In many cases, a mixture of different products is necessary because: (i) different chemical and physical properties can be combined; (ii) two or three elements can react to form products with higher reactivity than that of the initial elements; (iii) an undesirable property can be moderated by the presence of a second or third acid. ${ }^{44}$

Usually, inorganic acids are used in ultrasonic-assisted extraction procedures. The nitric and hydrochloric acids are the most used, the first is mainly used for its oxidizing character and the second because of its complexing character; these properties, when combined, improve the extraction yields ${ }^{44}$ However, in recent years, the number of researchers using organic acids combined with inorganic acids, aiming for higher extraction yields, has increased and the results are promising. ${ }^{21,22,24}$

In a study performed by Santos et al. ${ }^{20}$ an ultrasonicassisted extraction procedure was applied to bean samples, and the best extraction results were obtained when an acid mixture composed of $\mathrm{HNO}_{3}, \mathrm{HCl}$, and $\mathrm{CH}_{3} \mathrm{COOH}$ $\left(0.5 \mathrm{~mol} \mathrm{~L}^{-1}\right)$ was used. Barros et al. ${ }^{12}$ proposed an ultrasonic-assisted extraction procedure in chicken feed samples using a mixture of diluted acids, and observed that the extraction solution composed of $\mathrm{HNO}_{3}, \mathrm{HCl}$, and $\mathrm{CH}_{3} \mathrm{COOH}\left(3.6 \mathrm{~mol} \mathrm{~L}^{-1}\right)$ also improved the extraction yield. Similar results were found by Santos et al. ${ }^{22}$ when an acid mixture composed of $\mathrm{HNO}_{3}, \mathrm{HCl}$, and $\mathrm{CH}_{3} \mathrm{COOH}$ $\left(1.0 \mathrm{~mol} \mathrm{~L}^{-1}\right)$ assisted by ultrasound was applied to the extraction of metals in shellfish samples.

\section{Procedure validation and application}

The limit of detection (LOD) and quantification (LOQ) were calculated as the concentration of analyte corresponding to three and ten times, respectively; the standard deviation of ten independent measurements of the analytical blank were divided by the slope of the calibration curve. ${ }^{44}$ The LODs and LOQs calculated are provided in Table 3. The precision was evaluated in terms of repeatability using the relative standard deviation (RSD) obtained by analyzing seven distinct extractions of the same sample. The RSD values obtained were: $2.9(\mathrm{Ca}) ; 3.4(\mathrm{Mg})$; $5.6(\mathrm{Cu}) ; 3.2(\mathrm{Fe}) ; 3.8(\mathrm{Mn})$; and $1.9 \%(\mathrm{Zn})$.

To evaluate the matrix effect and to determine the ideal calibration method for the quantification of the studied elements, the calibration curves were prepared using the external calibration method, with dilution of element standards in the media composed by $\mathrm{HNO}_{3}, \mathrm{HCl}$, and $\mathrm{CH}_{3} \mathrm{COOH}$ in the concentration and volume found in the optimization step. Calibration curves using the analyte addition method were prepared in the presence of cassava starch sample. All correlation coefficients were above 0.9987. Equations of the calibration curves are presented in Table 4. Statistical evaluation using the 
Table 3. Limits of detection and quantification for proposed procedure and total digestion using FS FAAS (fast sequential flame atomic absorption spectroscopy)

\begin{tabular}{lcccc}
\hline \multirow{2}{*}{ Element } & \multicolumn{2}{c}{ Proposed procedure } & \multicolumn{2}{c}{ Total digestion } \\
\cline { 2 - 5 } & LOD / $\left(\mathrm{mg} \mathrm{kg}^{-1}\right)$ & LOQ / $\left(\mathrm{mg} \mathrm{kg}^{-1}\right)$ & LOD / $\left(\mathrm{mg} \mathrm{kg}^{-1}\right)$ & $\mathrm{LOQ} /\left(\mathrm{mg} \mathrm{kg}^{-1}\right)$ \\
\hline $\mathrm{Ca}$ & 10.4 & 34.7 & 9.5 & 31.6 \\
$\mathrm{Mg}$ & 2.7 & 9.0 & 2.3 & 7.6 \\
$\mathrm{Cu}$ & 0.5 & 1.7 & 0.8 & 2.7 \\
$\mathrm{Fe}$ & 1.6 & 5.4 & 1.7 & 5.7 \\
$\mathrm{Mn}$ & 0.4 & 1.3 & 0.6 & 2.0 \\
$\mathrm{Zn}$ & 1.7 & 5.6 & 1.1 & 3.7 \\
\hline
\end{tabular}

LOD: limit of detection; LOQ: limit of quantification.

$t$-test was performed to compare the slopes obtained with the conventional external calibration and analyte addition method curves, showing that the two values do not present significant differences at a 95\% level of confidence, demonstrating that the analytes can be determined either by using the standard addition method or external calibration method. These results demonstrated that the external calibration method can be satisfactorily employed for determination of elements studied in cassava peels samples by FS FAAS.

For accuracy evaluation, CRM NIST 1515 (apple leaves) were used and the newly developed procedure was verified by comparing the generated results with those of microwave-assisted digestion. Results were obtained and considerations of the proposed procedure are described in Table 5. A statistical comparison using Student's $t$-test showed that there is no significant difference between the value obtained with the use of the developed procedure and the certified value, at $95 \%$ confidence level. Paired $t$-test was used to compare the results with a $95 \%$ confidence level. Through this test, there was not a significant difference between data generated by the two procedures.

After the optimization, the procedure was applied to the extraction $\mathrm{Ca}, \mathrm{Mg}, \mathrm{Cu}, \mathrm{Fe}, \mathrm{Mn}$, and $\mathrm{Zn}$ in cassava peel samples used to complement dairy cows' diets; results are shown in Table 6 and concentration ranges, in $\mathrm{mg} \mathrm{kg}^{-1}$, were: 1772-2538 for $\mathrm{Ca}$, 633-965 for $\mathrm{Mg}$, 46.8-128 for $\mathrm{Zn}$, 23.7-139 for Fe, 5.10-36.8 for Mn, and 5.90-11.2 for $\mathrm{Cu}$.

Comparing with the results obtained by Burns et al. ${ }^{45}$ the concentrations of $\mathrm{Fe}$ and $\mathrm{Zn}$ found in the cassava peels are higher than those found in the cassava roots, but smaller than those found in the cassava leaves. Ceni et al. ${ }^{46}$ evaluated the concentrations of $\mathrm{Ca}, \mathrm{Mg}, \mathrm{Fe}, \mathrm{Zn}, \mathrm{Cu}$ and $\mathrm{Mn}$ in roots of five cassava cultivars, and only the $\mathrm{Fe}$ concentrations were higher than those of the cassava peels found in this work.

Table 4. Analytical curves with different calibration methods

\begin{tabular}{lccc}
\hline Analyte & Media & Calibration equation & $\mathrm{R}^{2}$ \\
\hline $\mathrm{Ca}$ & conventional & $\mathrm{y}=(0.0167 \pm 0.0025) \mathrm{C}_{\mathrm{Ca}}+(0.0031 \pm 0.0011)$ & 0.9997 \\
& analyte addition & $\mathrm{y}=(0.0178 \pm 0.0029) \mathrm{C}_{\mathrm{Ca}}+(0.0322 \pm 0.0009)$ & 0.9999 \\
\hline $\mathrm{Mg}$ & conventional & $\mathrm{y}=(0.0392 \pm 0.0089) \mathrm{C}_{\mathrm{Mg}}+(0.0187 \pm 0.0041)$ & 0.9999 \\
& analyte addition & $\mathrm{y}=(0.0398 \pm 0.0076) \mathrm{C}_{\mathrm{Mg}}+(0.0265 \pm 0.0048)$ & 0.9991 \\
\hline $\mathrm{Cu}$ & conventional & $\mathrm{y}=(0.1168 \pm 0.0152) \mathrm{C}_{\mathrm{Cu}}+(0.0003 \pm 0.0012)$ & 0.9987 \\
& analyte addition & $\mathrm{y}=(0.1176 \pm 0.0137) \mathrm{C}_{\mathrm{Cu}}+(0.0084 \pm 0.0019)$ & 0.9999 \\
\hline $\mathrm{Fe}$ & conventional & $\mathrm{y}=(0.0880 \pm 0.0112) \mathrm{C}_{\mathrm{Fe}}+(0.0026 \pm 0.0005)$ & 0.9996 \\
$\mathrm{Mn}$ & analyte addition & $\mathrm{y}=(0.0884 \pm 0.0102) \mathrm{C}_{\mathrm{Fe}}+(0.0216 \pm 0.0007)$ & 0.9998 \\
\hline $\mathrm{Zn}$ & conventional & $\mathrm{y}=(0.1961 \pm 0.0179) \mathrm{C}_{\mathrm{Mn}}+(0.0009 \pm 0.0017)$ & 0.9999 \\
& analyte addition & $\mathrm{y}=(0.1972 \pm 0.0165) \mathrm{C}_{\mathrm{Mn}}+(0.0116 \pm 0.0015)$ & 0.9999 \\
\hline
\end{tabular}

$\mathrm{R}^{2}$ : correlation coefficient. 
Table 5. Concentration in the sample of CRM NIST 1515 apple leaves determined by the proposed procedure, and in the real sample determined by the proposed procedure and microwave assisted digestion (mean \pm standard deviation, $\mathrm{n}=3$ )

\begin{tabular}{|c|c|c|c|c|}
\hline \multirow{3}{*}{ Element } & \multicolumn{4}{|c|}{ Concentration / $\left(\mathrm{mg} \mathrm{kg}^{-1}\right)$} \\
\hline & \multicolumn{2}{|c|}{ CRM NIST 1515 (apple leaves) } & \multicolumn{2}{|c|}{ Real sample } \\
\hline & Certified value & Found value & Total digestion & Proposed procedure \\
\hline $\mathrm{Ca}$ & $15260 \pm 150$ & $15263 \pm 189$ & $1823 \pm 29$ & $1805 \pm 38$ \\
\hline $\mathrm{Mg}$ & $2710 \pm 80$ & $2718 \pm 68$ & $635 \pm 15$ & $633 \pm 19$ \\
\hline $\mathrm{Cu}$ & $5.64 \pm 0.24$ & $5.66 \pm 0.26$ & $10.8 \pm 0.4$ & $10.4 \pm 0.5$ \\
\hline $\mathrm{Fe}$ & $83 \pm 5$ & $84 \pm 2$ & $23.7 \pm 0.5$ & $24.5 \pm 0.6$ \\
\hline $\mathrm{Mn}$ & $54 \pm 3$ & $53 \pm 2$ & $9.05 \pm 0.17$ & $8.85 \pm 0.27$ \\
\hline $\mathrm{Zn}$ & $12.5 \pm 0.3$ & $12.1 \pm 0.2$ & $48.3 \pm 0.2$ & $49.3 \pm 0.5$ \\
\hline
\end{tabular}

Table 6. Concentration in real samples as determined by the proposed procedure (mean \pm standard deviation, $\mathrm{n}=3$ )

\begin{tabular}{lcccccc}
\hline \multirow{2}{*}{ Sample } & \multicolumn{5}{c}{ Concentration $/\left(\mathrm{mg} \mathrm{kg}^{-1}\right)$} \\
\cline { 2 - 7 } & $\mathrm{Ca}$ & $\mathrm{Mg}$ & $\mathrm{Cu}$ & $\mathrm{Fe}$ & $\mathrm{Mn}$ & $\mathrm{Zn}$ \\
\hline 1 & $2066 \pm 45$ & $819 \pm 15$ & $7.07 \pm 0.31$ & $120 \pm 3.0$ & $13.2 \pm 0.38$ & $52.9 \pm 0.4$ \\
2 & $2538 \pm 38$ & $928 \pm 15$ & $6.17 \pm 0.19$ & $69.7 \pm 1.7$ & $8.28 \pm 0.16$ & $47.1 \pm 0.5$ \\
3 & $1979 \pm 41$ & $730 \pm 19$ & $5.90 \pm 0.26$ & $36.8 \pm 0.6$ & $5.10 \pm 0.10$ & $46.8 \pm 0.6$ \\
4 & $1907 \pm 44$ & $687 \pm 17$ & $6.24 \pm 0.28$ & $35.4 \pm 1.1$ & $6.94 \pm 0.25$ & $52.4 \pm 0.4$ \\
5 & $2512 \pm 39$ & $910 \pm 16$ & $7.91 \pm 0.24$ & $55.3 \pm 1.4$ & $18.5 \pm 0.5$ & $77.6 \pm 1.1$ \\
6 & $2507 \pm 42$ & $965 \pm 21$ & $9.36 \pm 0.25$ & $139 \pm 2.0$ & $36.8 \pm 1.2$ & $128 \pm 2.0$ \\
8 & $1801 \pm 40$ & $929 \pm 13$ & $11.2 \pm 0.35$ & $24.7 \pm 0.5$ & $14.9 \pm 0.3$ & $49.6 \pm 0.7$ \\
9 & $1805 \pm 46$ & $633 \pm 14$ & $10.4 \pm 0.52$ & $24.0 \pm 0.4$ & $8.77 \pm 0.28$ & $49.1 \pm 0.2$ \\
\hline
\end{tabular}

1: Teixeira de Freitas; 2: Nova Viçosa: 3: Alcobaça; 4: Eunapolis; 5: Mucuri; 6: Itamaraju; 7: Itapetinga; 8: Aspergillus niger-bioprocessed, Itapetinga; 9: Aspergillus oryzae-bioprocessed, Itapetinga.

The cassava peel samples analyzed in this study showed similar concentrations of $\mathrm{Fe}, \mathrm{Cu}, \mathrm{Mn}$ and $\mathrm{Zn}$, and higher $\mathrm{Ca}$ and $\mathrm{Mg}$ concentrations when compared to other alternative foods used to feed lactating cows, such as rice husk and sorghum,${ }^{47}$ and sugar cane bagasse. ${ }^{48}$

\section{Conclusions}

The mixture design with minimal restrictions helped to develop an analytical procedure to determine elements in cassava peel samples based on ultrasound- and microwave-assisted extraction with diluted acids. The proposed procedure was shown to be quick, efficient, inexpensive, and environmentally safer when compared with conventional procedures. The results obtained in this study are relevant because they provide information to animal nutrition researchers and to small and medium farmers, considering that information on element contents in agricultural residue such as cassava peel is scarce.

\section{Acknowledgments}

The authors would like to acknowledge the financial support provided by Fundação de Amparo à Pesquisa do Estado da Bahia (FAPESB), Conselho Nacional de Desenvolvimento Científico e Tecnológico (CNPq), Coordenação de Aperfeiçoamento de Pessoal de Nível Superior (CAPES), Financiadora de Estudos e Projetos (FINEP), and Santa Cruz State University (UESC).

\section{References}

1. Evans, E. H.; Horstwood, M.; Pisonero, M. J.; Smith, C. C. M.; J. Anal. At. Spectrom. 2013, 29, 779.

2. Oliveira, E.; J. Braz. Chem. Soc. 2011, 14, 174.

3. Bader, N. R.; Zimmermann, B.; Adv. Appl. Sci. Res. 2012, 3, 1733.

4. Rocha, D. L.; Batista, A. D.; Rocha, F. R. P.; Donati, G. L.; Nobrega, J. A.; Trends. Anal. Chem. 2013, 45, 79. 
5. Santos, W. P. C.; Santos, D. C. M. B.; Fernandes, A. P.; Korn, M. G. A.; Food Anal. Methods 2012, 6, 1133.

6. Souza, S. N. P.; Nascentes, C. C.; Costa, L. M.; Anal. Methods 2013, 5, 6411 .

7. Bizzi, C. A.; Flores, E. M. M.; Nóbrega, J. A.; Oliveira, J. S. S.; Schmidt, L.; Mortari, S. R.; J. Anal. At. Spectrom. 2014, 29 , 332.

8. Leme, A. B. P.; Bianchi, S. R.; Carneiro, R. L.; Nogueira, A. R. A.; Food Anal. Methods 2014, 7, 1009.

9. Bizzi, C. A.; Nóbrega, J. A.; Barin, J. S.; Oliveira, J. S. S.; Schmidt, L.; Mello, P. A.; Flores, E. M. M.; Anal. Chim. Acta 2014, 837, 16.

10. Amais, R. S.; Virgilio, A.; Schiavo, D.; Nóbrega, J. A.; Microchem. J. 2015, 120, 64.

11. Hartwig, C. A.; Pereira, R. M.; Rondan, S. M.; Cruz, S. M.; Duarte, F. A.; Flores, E. M. M.; Mesko, M. F.; J. Anal. At. Spectrom. 2015, 31, 523.

12. Barros, J. A. V. A.; Souza, P. F.; Schiavo, D.; Nóbrega, J. A.; J. Anal. At. Spectrom. 2016, 31, 602.

13. Machado, R. C.; Pereira-Filho, E. R.; Nogueira, A. R. A.; J. Braz. Chem. Soc. 2016, 27, 1273.

14. Bendicho, C.; Calle, F. L.; Costas, M.; Cabaleiro, N.; Lavilla, I.; Trends Anal. Chem. 2012, 31, 50.

15. Tiwari, B.; Trends Anal. Chem. 2015, 71, 100.

16. Bezerra, M. A.; Castro, J. T.; Macedo, R. C.; Silva, D. G.; Anal. Chim. Acta 2010, 670, 33.

17. Leardi, R.; Anal. Chim. Acta 2009, 652, 161.

18. Lonni, A. A. S. G.; Longhini, R.; Lopes, G. C.; Mello, J. P. C.; Scarminio, I. S.; Anal. Chim. Acta 2012, 719, 57.

19. Pauli, E. D.; Barbieri. F.; Garcia, P. S.; Madeira, T. V.; Junior, V. R. A.; Scarminio, I. S.; Camara, C. A. P.; Food Res. Int. 2014, $61,112$.

20. Santos, W. P. C.; Castro, J. T.; Bezerra, M. A.; Fernandes, A. P.; Ferreira, S. L. C.; Korn, M. G. A.; Microchem. J. 2009, 91, 153.

21. Bezerra, M. A.; Souza, A. D. S.; Oliveira, R. V.; Oliveira, D. M.; Cardoso, L. A. M.; Filho, H. R. S.; An. Acad. Bras. Cienc. 2015, 87, 3 .

22. Santos, W. P. C.; Hatje, V.; Santil, D. S.; Fernandes, A. P.; Korn, M. G. A.; Souza, M. M.; Microchem. J. 2010, 95, 169.

23. Lavilla, I.; Costa, M.; Corderí, S.; Sanchez, G.; Bendicho, C.; Talanta 2012, 93, 116.

24. Saleh, M. A. D.; Berto, D. A.; Padilha, P. M.; Ultrason. Sonochem. 2013, 20, 1353.

25. Szymczycha-Madeja, A.; Welna, M.; Pohl, P.; Food Anal. Methods 2014, 7, 2051.

26. Santos, L. C. M. B.; Carvalho, L. S. B.; Lima, D. C.; Leão, D. J.; Teixeira, L. S. G.; Korn, M. G. A.; J. Food Compos. Anal. 2014, 34, 75.

27. Frena, M.; Quadros, D. P. C.; Castilho, I. N. B.; Goes, J. S.; Borges, D. L. G.; Welz, B.; Madureira, L. A. S.; Microchem. J. 2014, 117, 6 .
28. Niedzielski, P.; Zielinska-Dawidziak, M.; Kozak, L.; Kowalewski, P.; Szlachetka, B.; Zalicka, S.; Wachowiak, W.; Food Anal. Methods 2014, 7, 2023.

29. Villa, J. E. L.; Pereira, C. D.; Cadore, S.; Microchem. J. 2015, $121,199$.

30. Trindade, A. S. N.; Dantas, A. F.; Lima, D. C.; Ferreira, S. L. C.; Teixeira, L. S. G.; Food Chem. 2015, 185, 145.

31. Lopes, G. S.; Silva, F. L. F.; Grinberg, P.; Sturgeon, R. E.; J. Braz. Chem. Soc. 2016, 27, 1229.

32. Nascentes, C. C.; Korn, M.; Sousa, C. S.; Arruda, M. A. Z.; J. Braz. Chem. Soc. 2001, 12, 57.

33. Statistica, Data Analysis Software System; Statsoft: Tulsa, USA, 2001.

34. Derringer, G.; Suich, R.; J. Qual. Technol. 1980, 12, 214.

35. Santos, D. J.; Krug, F. J.; Godoi, M.; Appl. Spectrosc. Rev. 2006, $41,305$.

36. Benson, R. L.; McKelvie, I. D.; Hart, B. T.; Anal. Quim. Acta 1994, 291, 233.

37. Ye, X.; Li, L.; Anal. Chem. 2012, 84, 6181.

38. Santos, Q. O.; Novaes, C. G.; Bezerra, M. A.; Lemos, V. A.; Moreno, I.; Silva, D. G.; Santos, L.; J. Braz. Chem. Soc. 2010, 21,2340 .

39. Ashoka, S.; Peake, B. M.; Bremner, G.; Hageman, K. J.; Reid, M. R.; Anal. Chim. Acta 2009, 653, 191.

40. Chang, L. F.; Jiang, S. J.; Sahayam, A. C.; J. Chromatogr. A 2007, 1176, 143.

41. Krishna, M. V. B.; Chandrasekaran, K.; Karunasagar, D.; Anal. Methods 2012, 4, 1401.

42. Krishna, M. V. B.; Chandrasekaran, K.; Venkateswarlu, G.; Karunasagar, D.; Anal. Methods 2012, 4, 3290.

43. Krug, F. J.; Rocha, F. R. P.; Métodos de Preparo de Amostras. Fundamentos sobre o Preparo de Amostras Orgânicas e Inorgânicas para Análise Elementar; Editora EditSBQ: São Paulo, 2016.

44. Belter, M.; Sajnóg, A.; Barałkiewicz, D.; Talanta 2014, 129, 606.

45. Burns, A. E.; Gleadow, R. M.; Zacarias, A. M.; Cuambe, C. E.; Miller, R. E.; Cavagnaro, T. R.; J. Agric. Food Chem. 2012, 60, 4946.

46. Ceni, G. C.; Colet, R.; Peruzzolo, M.; Witschinski, F.; Tomicki, L.; Barriquelo, A. L.; Valduca, E.; Aliment. Nutr. 2009, $20,107$.

47. Andrigueto, J. M.; Perli, L.; Minardi, I.; Souza, A.; Filho, A. B.; Nutrição Animal: as Bases e os Fundamentos da Nutrição Animal - os Alimentos, $4^{\mathrm{a}}$ ed.; Editora Nobel: São Paulo, 1981.

48. Campos, M. M.; Borges, A. L. C. C.; Gonçalves, L. C.; Alimentos para Gado de Leite, $1^{\mathrm{a}}$ ed.; Gonçalves, L. C.; Borges, I.; Ferreira, P. D. S., eds.; Editora FEPMVZ: Belo Horizonte, 2009, p. 7.

Submitted: September 28, 2017 Published online: November 27, 2017 